\title{
MERCADO INFORMAL NA FRONTEIRA BRASIL - PARAGUAI: SHOPPING CALÇADÃO MERCOSUL ${ }^{1}$
}

\begin{abstract}
Álvaro Banducci Júnior ${ }^{2}$
\section{RESUMO}

As cidades de Ponta Porã (BR) e Pedro Juan Caballero (PY), separadas por fronteira seca, constituem centros conurbados, limitados por uma longa avenida que acompanha a ocupação humana de ambos os lados. O turismo de compras, importante setor da economia local, fez emergir do lado paraguaio, a partir de 1980, um significativo comércio informal de importados, caracterizado por ambulantes e pequenos comerciantes que instalaram bancas na principal rua comercial da cidade. Na década de 1990, uma crise se abateu sobre a economia de Ponta Porã, fazendo com que alguns comerciantes reivindicassem a instalação de comércio popular semelhante ao paraguaio no lado brasileiro. Com isso, nasceu o Primeiro Shopping Calçadão Mercosul, centro comercial instalado na linha de divisa entre os países, porém em solo brasileiro. Ocupado por lojistas de distintas nacionalidades, o Shopping oferece produtos idênticos aos vendidos no Paraguai e acaba por disputar a mesma clientela, pois se estrutura segundo regras e condições muito semelhantes às do comércio vizinho. Este artigo aborda o modo como está organizado esse comércio, como se regula frente às normatizações públicas brasileiras e como interage com o mercado paraguaio. Da mesma forma, pretende discutir de que maneira as categorias legal e ilegal, lícito e ilícito são articuladas num contexto em que se pratica uma modalidade de comércio permitida apenas no lado paraguaio e como, numa situação de liminaridade, são reafirmadas as representações sobre o "outro".
\end{abstract}

Palavras-chave: Paraguai. Fronteira. Mercado Informal. Legalidade e Ilegalidade.

${ }^{1}$ Este trabalho foi apresentado, numa primeira versão, na $28^{\mathrm{a}}$ Reunião Brasileira de Antropologia, realizada entre os dias 02 e 05 de julho de 2012, na cidade de São Paulo-SP. O estudo resulta de uma pesquisa abrangente sobre relações sociais e identidade na fronteira Brasil-Paraguai, associada às atividades de professor visitante na Universidade de Campinas - UNICAMP (2011-2012), cuja realização se viabilizou mediante o apoio financeiro do CNPq através de Bolsa de Pesquisa Sênior. ${ }^{2}$ Professor Adjunto da Universidade Federal de Mato Grosso do Sul - UFMS e professor colaborador do Programa de Pós-Graduação em Antropologia da Universidade Federal da Grande Dourados - UFGD. E-mail: banducci@uol.com.br. 


\section{INFORMAL MARKET ON THE BRAZILIAN AND PARAGUAYAN BORDER: SHOPPING CALÇADÃO MERCOSUL}

Separated by a land border, the cities of Ponta Porã [BR] and Pedro Juan Caballero [PY] are limited by a long avenue that accompanies human occupation on both sides. The shopping tourism, an important sector of the local economy, permitted, since 1980, the emergence of a significant informal commerce on the Paraguayan side, characterized by street vendors and small shopkeepers who opened stalls on the main commercial street of the city. In the 1990s, Ponta Porã was hit by a financial crisis, leading some merchants to demand the installation of a popular commerce similar to the Paraguayan side. This movement gave birth to the Shopping Calçadão Mercosul, a commercial center installed on the border of the two countries, but on the Brazilian soil. Occupied by shopkeepers of different nationalities, this Shopping Center offers the same products sold on the Paraguayan side. Since it is structured in terms of rules and conditions in much the same way as the neighbor's commerce, there was the beginning of a dispute over the customers. So, this article brings into questions how this commerce is structured, how it is regulated in conformity with the Brazilian governmental norms, and how it interacts with the Paraguayan market. It also intends to discuss the way the categories legal and illegal, licit and illicit are articulated in a context where a certain type of commerce which is only permitted on the Paraguayan side of the border is practiced on the Brazilian side as well, and how the representations of the "other" are reaffirmed in a borderline situation like this.

Keywords: Brazil. Paraguay. Border. Informal Market. Legality and Illegality. 


\section{Introdução}

A cidade de Pedro Juan Caballero (PY), na divisa com Ponta Porã (BR), em Mato Grosso do Sul, nasce com uma forte aptidão comercial. De fornecedora de produtos importados para vilas e fazendas fronteiriças, no final do século XIX, torna-se, desde a segunda metade do século XX,um importante polo reexportador do mercado paraguaio. Estimulado pelo turismo de compras, a cidade tem seu comércio expandido e consolidado, atraindo imigrantes asiáticos, árabes, dentre outros que, vindos do município de Ciudad del Este, capital do Departamento de Alto Paraná (PY), ou diretamente de seus países de origem, cedo estendem para essa região de fronteira as redes internacionais que mobilizam o comércio de produtos legais e de contrabando.

Este trabalho se volta para a análise do avanço desse comércio, na fronteira do Brasil com o Paraguai, que constitui um elo na cadeia que Ribeiro (2009) denomina de globalização popular, definido por ele como redes de comércio e mercados globais mobilizados por gente do povo, sendo, em geral, considerados ilegais. O propósito do artigo é identificar o modo como o comércio de importados se expande para o território brasileiro, favorecendo a criação de um mercado popular semelhante ao que existe na vizinha Pedro Juan Caballero, e como as representações nacionais, do "nós" e do "outro", são manipuladas para estabelecer parâmetros de legitimidade num contexto em que prevalecem práticas movidas pela informalidade. Inserido em território nacional, contando com o aval da Prefeitura de Ponta Porã, para a qual contribui com uma série de taxas públicas, o mercado funciona segundo os moldes do comércio paraguaio. Como tal, atua para além do limite do considerado oficialmente lícito. O comércio popular de Ponta Porã constitui-se, parafraseando Renoldi (2009), num mercado legal de produtos ilegais.

$\mathrm{O}$ artigo aborda as razões que levaram à construção desse mercado, o modo como se estabeleceu e a maneira como os lojistas se posicionam frente ao comércio similar praticado no Paraguai. Os levantamentos de campo ocorreram nos anos de 2011 e 2012, consistindo de três visitas às cidades gêmeas de Ponta Porã e Pedro Juan Caballero. Neste percurso, além da observação direta dos mercados populares voltados para o turismo e seu funcionamento, do contato com setores da administração pública de ambos os países, das conversas informais 
com comerciantes e citadinos fronteiriços, foram realizadas entrevistas com lojistas brasileiros e paraguaios - sobretudo do mercado popular, mas também do mercado formal - bem como trabalhadores do comércio turístico, moradores e agentes públicos de ambas as cidades.

\section{Formação de povoados e as práticas ilícitas na fronteira}

O território que compreende a fronteira do Brasil com o Paraguai, na divisa com o Mato Grosso do Sul, foi uma área rica em campos de pastagens, reservas de quebracho (Schinopsis brasiliensis Engl.) e, sobretudo, de ervais nativos, cuja exploração mais intensa, dirigida ao mercado exportador, teve início ao final da década de 1850, quando da abertura do rio Paraguai à livre navegação. A partir de então a região teve facilitado o acesso à Argentina, principal mercado consumidor da indústria ervateira (QUEIROZ, 2009). O Paraguai, nesse período, possuía uma produção expressiva e comércio consolidado de ervamate (Ilex-paraguaienses). Com o advento da Guerra da Tríplice Aliança esse comércio recrudesceu, para ser retomado, sob outros moldes, ao término do conflito, que resultou em uma redefinição de fronteiras.

O estabelecimento de novos limites nacionais entre o Brasil e o Paraguai, tendo o primeiro anexado um extenso e generoso território de ervais $^{3}$, rearranja o mapa da economia ervateira, sendo que o então sul de Mato Grosso ${ }^{4}$ passa a assumir posição de destaque entre os exportadores desse produto a partir da exploração latifundiária. A expansão da indústria ervateira e da atividade comercial interfronteira, impulsionada pelo Tratado de Livre Comércio, firmado entre Brasil e Paraguai em 1883, que franqueava o trânsito de mercadorias entre os dois países, contribuiu para o incremento da economia de Concepción, no Paraguai, da mesma forma que foi determinante no surgimento das cidades gêmeas de Ponta Porã e Pedro Juan Caballero entre a última década do século XIX e o início do século XX.

${ }^{3}$ De acordo com Goiris (1999), as terrras anexadas pelo Brasil, pertencentes anteriormente ao que viria a ser o Departamento de Amambay (PY), somam mais de $150 \mathrm{mil} \mathrm{Km}^{2}$.

${ }^{4}$ No ano de 1977, o antigo Mato Grosso teve sua porção meridional desmembrada, constituindo o atual Estado de Mato Grosso do Sul. 
Separados por fronteira seca, esses núcleos urbanos têm sua história marcada pela atividade ervateira e pelo comércio a ela associado, baseados na exportação de produtos nativos e na importação de mercadorias europeias e de outros centros industriais (BENÍTEZ, 2008). Empresas monopolistas como a Industrial Paraguaia S.A. e a Cia Matte Larangeira, que detinham a posse ou a concessão de vastíssimo território de ervais, exerceram forte domínio sobre o mercado. Seu poder era de tal ordem que influenciaram nas políticas de Estado e controlaram por um longo período a ocupação da área sob seu domínio. Ao mesmo tempo, sua presença serviu para impulsionar o comércio, criar infraestrutura portuária e vias de circulação na fronteira, facilitando o escoamento da produção e o acesso à região.

O empreendimento ervateiro desempenhou, desse modo, um duplo e paradoxal papel na ocupação da fronteira. Os ervais atraíram levas de migrantes paraguaios e brasileiros que fugiam da miséria e de conflitos internos em seus países de origem (GUILLEN, 1991, p. 228). Ao mesmo tempo, a população que afluía a esse território, encontrava violenta resistência à ocupação das terras, concentradas que estavam nas mãos do latifúndio ervateiro. Essa condição de exclusão, de trabalhadores e posseiros, e de controle sobre comerciantes e migrantes, contribuiu fortemente para induzir práticas clandestinas e de resistência.

De acordo com Lamberti (2006), as fronteiras, de modo geral, constituem lugares propensos ao ilícito 5 .

\footnotetext{
${ }^{5}$ As categorias de oposição lítico/ilícito, legal/ilegal e formal/informal, tal como demonstram Ribeiro (2009 e 2010), Pinheiro-Machado (2008 e 2009) e Noronha (2003),estão envolvidas em grande complexidade conceitual e empírica. Não raro as linhas que as separam são transpostas ou se confundem. Práticas e bens considerados ilegais num determinado contexto ou país podem ser vistos como legítimos em outros. Para efeitos deste estudo, a categoria ilícito será tomada, conforme disposto por Pinheiro-Machado (2008), em contraposição à noção de informalidade. Esta última, segundo a autora, "diz respeito às práticas de trabalho e mercado nãoreguladas pelo Estado, enquanto que, a categoria ilícito refere-se às ações de contrabando e à pirataria, consideradas criminosas sob um ponto de vista legal. No escopo jurídico, ambas podem ser consideradas ilegais, embora no aspecto moral haja uma gradação relevante entre elas" (2008, p. 05). Se o lícito (categoria moral e socialmente definida) não necessariamente corresponde à esfera do legal (definição político-jurídica) - a atividade de sacoleiro, p.ex., pode ser vista como lícita pelos atores nela envolvidos e como crime pelos agentes do Estado -; o ilícito pode não coincidir integralmente com a noção de ilegalidade. Ainda que ambas remetam ao terreno do ilegítimo, práticas ilícitas são classificadas segundo um amplo espectro
} 
O comércio entre cidades-gêmeas (e o contrabando) é prática comum em todas as áreas de fronteira, não sendo específico do Brasil ou do Paraguai, e deriva tanto do fluxo de bens e pessoas, como das possibilidades de usufruir as facilidades decorrentes das diferentes normas e legislações proporcionadas pela existência de dois estados-nacionais (LAMBERTI, 2006, p. 32).

Assim, uma área de fronteira, que costuma ser território propício a ações ilegais, tornava-se, em decorrência do poder da indústria ervateira e das políticas regulatórias e fundiárias do Estado, em área propensa ao ilícito. Se o comércio interfronteiras desde cedo foi marcado por transações que não se amparavam na legalidade ${ }^{6}$, são, sobretudo, as medidas dos Estados brasileiro e paraguaio, orientadas para reforçar os poderes de elites locais no final do século XIX, que irão estimular o exercício de práticas ilícitas nessa área.

A concentração de terras, o favorecimento político e a pressão por parte da indústria ervateira paraguaia pelo fim do Tratado do Livre Comércio, que a seus olhos beneficiava a indústria brasileira, ao mesmo tempo em que atendiam aos interesses ervateiros colocavam uma grande massa da população em condição de exploração e marginalidade, incentivando a ação clandestina, fosse em relação à produção ervateira propriamente dita e sua distribuição, fosse em relação ao comércio de bens entre os dois países.

Ribeiro (2009 e 2010), ao discutir a constituição do sistema mundial não-hegemônico, estabelece uma reflexão importante sobre o lugar e o papel do Estado na instituição e regulação dos espaços de legalidade. Ainda que tratando das relações no capitalismo contemporâneo, sua discussão pode ser aplicada ao contexto da fronteira Brasil-Paraguai no final do século XIX. Para o autor, no debate sobre a legalidade e a ilegalidade, e sobre práticas como o contrabando, a "entidade central em jogo é o Estado. São as elites estatais que têm, ao longo dos

moral que pode torná-las socialmente aceitáveis ou objeto de recriminação. Assim, o contrabando pode ser visto como ilegítimo, porém deve ser diferenciado de práticas como o comércio de armas e o tráfico de drogas e de pessoas, que pressupõem a violência e resultam em consideráveis danos sociais.

${ }^{6}$ Mesmo quando o livre comércio permitia a entrada de produtos paraguaios em território brasileiro isentos de impostos, "era corriente que productos importados de Europa (ponchos, botas y zapatos, conservas, alimentos) se introducían como 'mercaderías paraguayas' a dicha província” (RAMIREZ, Apud MARTINS, 2007, p. 61), ou seja, como contrabando. 
séculos, mantido o monopólio da definição e da regulação da legalidade/ ilegalidade" (2010: 24).

As regulamentações do Estado geram contrapartidas, que se manifestam mediante práticas evasivas, como das redes ilegais, ou de adesão, através de redes de legalidade, decorrentes de relações desiguais historicamente construídas entre diferentes setores da sociedade. São as leis do Estado, portanto, brasileiro ou paraguaio que, visando favorecer setores da elite ervateira, acabaram por promover fluxos no âmbito da clandestinidade no final do século $\mathrm{XIX}^{7}$ e que ainda hoje definem, com base em interesses de setores específicos do capital transnacional, o lugar da legalidade no mercado internacional.

O comércio de mercadorias europeias voltadas para o abastecimento de fazendas e pequenos povoados, a exportação da erva-mate, do couro, dentre outros produtos, fizeram-se substituir por outros fluxos de mercadorias, tais como o café e a soja, e de atividades, como a industrial e o turismo. O vínculo com o capitalismo internacional, estabelecido no momento da formação das duas cidades, nunca deixou de existir. Atualmente Pedro Juan Caballero e Ponta Porã compreendem mercados regionais conectados a circuitos de produção e comércio de escala planetária, constituindo um elo de poderosas redes de circulação de mercadorias e pessoas estimuladas pelo mercado de reexportação, cuja base é o turismo de compras.

\section{O turismo de compras em Pedro Juan Caballero}

O município de Ponta Porã possui atualmente 80.433 habitantes (IBGE, 2010), número pouco inferior ao do Departamento de Amambay, cuja capital é Pedro Juan Caballero, com88.189 habitantes (DGEEC, 2002). As sedes dos municípios constituem cidades-gêmeas, separadas apenas por um largo canteiro central, margeado por avenidas, espaço esse que favorece e estimula o livre trânsito de

${ }^{7}$ O fim do Tratado do Livre Comércio (1898) afetou diretamente a burguesia comercial paraguaia. Impedidos de vender seus produtos no Brasil, senão com altos impostos aduaneiros, os comerciantes, a fim de prosseguir com seus negócios, dão "inicio a uma practica que se extiende hasta nuestros dias, la del contrabando, pues luego de intalados em Punta Porã (atual PJC) los productos importados de forma ilegal eran introducidos en Brasil" (BENITEZ, 2008, p. 249). 
pessoas e bens entre os países. Junto à linha de divisa, na Avenida Dr. Francia, estabeleceu-se desde muito cedo o comércio de importados na cidade de Pedro Juan Caballero, prenunciando o caráter comercial que balizaria a economia de ambas as cidades.

A vocação comercial de Pedro Juan Caballero se consolidou através dos anos, alimentada pelo mercado da erva-mate, que em território brasileiro passou a ser explorada por cooperativas de pequenos produtores (QUEIROZ, 2008); pela cafeicultura, cuja produção implicou na instalação da Companhia Americana de Fomento Econômico - CAFÉ, no Paraguai; além de outras atividades legais ou ilegais, como a produção de cana-de-açúcar, a exploração madeireira e o cultivo da maconha (cannabis sativa) (GOIRIS, 1999), na década de 1960. A condição de fronteira internacional foi decisiva para a dinâmica econômica do Departamento de Amambay, pois, como indica Lamberti (2006), do ponto de vista político e econômico a região estava isolada do restante do país, tendo se voltado para o mercado brasileiro. Assim, o comércio de produtos importados, no modelo reexportador, consistiu desde o final do século XIX numa das principais atividades econômicas desse território fronteiriço (Idem, p. 59).

A reexportação consiste na venda para o exterior de mercadorias importadas de outros países, independente de haverem sofrido transformação (LAMBERT, 2006).

É através da lógica da reexportação que o território conurbado de Pedro Juan Caballero conecta-se ao mundo e com as regiões ganhadoras através da comercialização de produtos de consumo de massa (ou de segunda linha) produzidos principalmente na porção asiática e produtos destinados a um mercado consumidor bastante seleto e composto por marcas reconhecidas internacionalmente (Idem, p.60).

O comércio reexportador ganha impulso, nessa área de fronteira, a partir da década de 1960, quando começa a atrair turistas brasileiros, em sua maioria provenientes do Sul de Mato Grosso ${ }^{8}$. A pavimentação

${ }^{8}$ Goiris (1999, p. 259), esclarece que "en la década del 60, los comerciantes pedrojuaninos consiguieron la promulgación del Decreto Ley 25.937, de 1962, que hizo reaccionar positivamente al comercio fronterizo. En realidad, ese decreto no contemplaba una zona franca para Pedro Juan Caballero, [tal como acontecia em Ciudad del Este (PENNER, 1998)], sino una liberación aduanera sobre mercaderías 
da rodovia BR 463, que liga as cidades gêmeas à Campo Grande, na ocasião a segunda cidade em importância no estado, e a chegada da linha férrea a Ponta Porã, na década de 1950, foram decisivos para o incremento dessa atividade comercial (GOIRIS, 1999). Os turistas estavam interessados em adquirir produtos "legítimos", de marcas internacionais famosas. Nesse período, as casas do comércio refinado de Pedro Juan Caballero ofereciam marcas tais como Adidas, Lee, Solingen, além de produtos como bebidas, tecidos finos e outros, cujo diferencial, além do preço acessível, era seu caráter genuíno. No dizer de um antigo comerciante local, o turista buscava os produtos importados por serem de baixo custo e de qualidade superior, resistentes e duráveis (MARTINS, 2007, p. 62). Como tal, as mercadorias mais cobiçadas eram de origem americana e europeia. No entanto, a partir da década de 1970, produtos de origem asiática começam a competir com os de outra procedência no mercado pedrojuanino.

Nas décadas seguintes, o turismo consolida-se como importante atividade da economia de Pedro Juan Caballero, com efeitos em cadeia para toda a região fronteiriça. $\mathrm{O}$ setor hoteleiro e de serviços, como transporte, bares e restaurantes, se desenvolve de forma expressiva na cidade de Ponta Porã, que também emprega um número considerável de trabalhadores no comércio da cidade vizinha ${ }^{9}$. O setor financeiro cresce nas duas cidades, em função das demandas por trocas monetárias (LAMBERTI, 2006).

Os comerciantes paraguaios são beneficiados, na década de 1970, pelo Regime de Turismo. Trata-se de um artifício tributário instituído no Paraguai, e admitido pelo Mercosul, que incentiva, através de considerável redução de impostos, o comércio de produtos importados destinados ao mercado turístico. Como aponta Martins, esse

de procedencia brasileña. Estos productos brasileños no pagaban ICM - Imposto sobre Circulação de Mercadorias; IPI - Imposto sobre Produtos Industrializados y ni siquiera se requería el Impuesto a la Renta".

${ }^{9}$ Em estudo voltado para o mercado de trabalho nessa região de fronteira (DUTRA \& GOETTERT, 2009), apresentam dados expressivos sobre a mão-de-obra brasileira empregada no comércio de Pedro Juan Caballero no ano de 2006. De acordo com o vice-presidente da Câmara de Comércio daquela cidade, "em relação ao comércio turístico, apenas no micro centro da cidade, há 4.500 pessoas trabalhando, dentre as quais 900 são brasileiros e brasileiras, com maior destaque para as últimas (cerca de $80 \%$ ). Se contarmos o comércio em geral, e não apenas o de reexportação, esse número sobe para $1.500 "$ (2009 p. 6). 
instrumento "[...] cria as bases para transformar a reexportação em um dos setores mais importantes da economia nacional" (2007, p. 68-9).

O mercado de produtos importados em expansão atrai para a região, a partir da década de 1980, imigrantes de origem árabe e asiática. Estes últimos, procedentes em sua maioria de Taiwan, de Hong Kong e da Coreia (MARTINS, 2007), articulados em amplas e complexas redes informais de interesses mútuos (PINHEIRO-MACHADO, 2008; RABOSSI, 2004 e SILVA, 2009), ganham proeminência no comércio local. A importação de mercadorias, sobretudo aquelas voltadas para o mercado popular, passa a ser controlada pelos grupos asiáticos, que se tornam, mais do que comerciantes, distribuidores regionais.

Ainda na década de 1980 e no início de 1990, o comércio de produtos importados tornou-se extremamente lucrativo, atraindo não apenas turistas como também sacoleiros procedentes de diferentes estados brasileiros, tais como São Paulo, Goiás, Minas Gerais e outros. As ruas de Pedro Juan Caballero foram tomadas por vendedores ambulantes e por pequenos comerciantes, instalados nas casillas, bancas de alumínio que comercializam toda espécie de produtos populares, tais como CDs, eletrônicos, vestuário, brinquedos e outras bugigangas oriundas principalmente do mercado asiático. As casillas expandiram espacialmente a ponto de formarem verdadeiras galerias nas calçadas da Avenida Dr. Francia, a principal via de lojas de importados, impedindo, em alguns locais, o acesso do pedestre à rua. Muitos desses estabelecimentos constituem uma extensão "informal" das lojas em frente às quais se instalam, sendo uma alternativa de ganhos para os proprietários do comércio formal.

Aos poucos as casillas atravessaram a via pública, sendo instaladas no canteiro central que separa os dois países. Em curto período esse novo bloco de lojas havia duplicado, estando um pavilhão voltado para o lado paraguaio enquanto que outro, justaposto ao anterior, abria suas portas em direção à linha de divisa, ou seja, para o Brasil. Esse aglomerado de boxes de lata, madeira e alumínio, dominado sobretudo por comerciantes paraguaios, mas também por estrangeiros, formou um grande camelódromo, frequentado por moradores locais, turistas e sacoleiros. No período da pesquisa havia por volta de 700 módulos instalados no comércio paraguaio, sendo o seu número bastante flutuante, pois começava a se implantar,na área da divisa, o Projeto Linha Internacional, um complexo comercial popular, cuja construção 
é financiada pela União Europeia, e que naquele momento estimulava o surgimento constante de novas casillas, pré-condição para os comerciantes reivindicarem um módulo nonovo espaço comercial.

O declínio no turismo, que tem início na segunda metade da década de 1990 e se estende até meados da década de 2000, decorrente das oscilações da moeda brasileira, afetou diretamente o mercado de reexportação, estancando o crescimento da economia pedrojuanina. $\mathrm{O}$ comércio popular, entretanto, manteve-se ativo e nos últimos anos se viu impulsionado, assim como o mercado de importados em geral, por novas conjunturas da economia brasileira.

\section{O turismo de compras e a economia de Ponta Porã}

No ano de 1995, com o dólar americano cotado a aproximadamente $\mathrm{R} \$$ 1,00, a atividade comercial em Pedro Juan Caballero encontrava-se altamente aquecida. Dados da Secretaria da Câmara da Indústria e Comércio de Pedro Juan Caballero, relativos ao ano anterior, indicavam que o comércio de importados no Paraguai, mobilizava uma média diária de 3.500 pessoas (LAMBERTI, 2006). Penner (1998), economista do Banco Central do Paraguai, em estudo sobre o movimento comercial e financeiro de Ciudad del Este no contexto da economia de reexportação, ressalta que

Entre 1991 y 1995, Ciudad del Este tuvo un crecimiento económico acelerado. La novedad era que, ya no se vendía solamente a turistas [...] sino que aparecieron en forma masiva los agentes que hicieron posible el aumento del comercio fronterizo, los compristas, que son pequeños comerciantes itinerantes que viajan desde diversas ciudades de Brasil y realizan compras en la ciudad con el objetivo de reventa en su país. (PENNER, 1998, p. 07).

Os "compristas", conhecidos por sacoleiros no Brasil, afluíam, do mesmo modo, à cidade fronteiriça de Pedro Juan Caballero, impulsionando o comércio de importados e o crescimento econômico da cidade paraguaia. O lado oposto da fronteira, no entanto, apresentava um cenário menos alentador. O comércio de Ponta Porã amargava uma crise aguda, com o fechamento crescente de lojas e o aumento inquietante no número de desempregados. 
Como relata uma lojista brasileira, “[...] naquela época a cota [para a aquisição e transporte de importados] era de U\$ 500. E não tinha essa fiscalização que tem hoje". Em outros termos, uma cota favorável ${ }^{10}$, que alimentava o desejo de turistas e de sacoleiros em realizar compras no Paraguai, aliada à facilidade de transporte das mercadorias para o Brasil, despertava o interesse por essa região de fronteira. Era significativo o número de sacoleiros, vindos de São Paulo, Goiás, Minas Gerais, além de outros estados brasileiros, que aportavam em caravanas de ônibus a Ponta Porã - Pedro Juan Caballero, descortinando uma rota de compras alternativa à de Ciudad del Leste Foz do Iguaçu, onde a fiscalização rigorosa, que ocorria na Ponte da Amizade $^{11}$, aumentava os riscos de apreensão das mercadorias.

\section{O Paraguai é aqui: Shopping Calçadão Mercosul}

Nesse período, por iniciativa do Conselho da Mulher Executiva, ligado à Associação Comercial de Ponta Porã, um grupo de empresárias, comerciantes, artesãs e outras profissionais associadas àquele organismo teve a ideia de instalar, no canteiro que compreende a zona neutra entre os dois países, um espaço para a comercialização de artesanatos e outros produtos locais, a exemplo do que acontecia no lado paraguaio. Sua meta era atrair turistas com destino à vizinha Pedro Juan Caballero.

A iniciativa do Conselho despertou o interesse da Prefeitura de Ponta Porã, que outorgou alvará para instalação e funcionamento do complexo comercial, e da Comissão Brasileira Demarcadora de Limites $^{12}$, que concedeu licença para a construção junto à divisa. A

\footnotetext{
${ }^{10} \mathrm{~A}$ cota brasileira de importação para o turista sofreu, segundo Penner (Apud. MARTINS, 2007 e PENNER, 1998), quatro variações desde 1992, quando foi estabelecida em U\$ 500. No final de 1995 foi reduzida a U\$ 250; em 1996 passou para U\$ 150 e, mais tarde, em 2005, estabilizou-se em U\$ 300.

${ }^{11}$ A "Ponte da Amizade", inaugurada em março de 1965, liga Foz do Iguaçu a Ciudad del Este, sendo o principal canal de circulação de mercadorias importadas e exportadas pelo Paraguai (RABOSSI, 2004). Como lembra Pinheiro-Machado (2004), o nome não condiz com o cotidiano da Ponte, pois sendo local de intensa circulação de mercadorias, em grande parte sob a forma de contrabando, é um espaço marcado pela tensão e o conflito.

${ }^{12}$ Comissão Brasileira Demarcadora de Limites é o órgão ligado ao Ministério das Relações Exteriores encarregados de demarcar e caracterizar os limites territoriais brasileiros. Existem duas Comissões, sendo que a segunda, possui subsede em Ponta Porã (MS) (ENGEL, 2012).
} 
proposta, que a princípio visava instalar uma cooperativa de mulheres, ganhou, no entanto, nova dimensão, transformando-se, no dizer de uma de suas idealizadoras, numa espécie de camelódromo. O projeto recebeu o nome imponente e bastante peculiar de Primeiro Shopping Calçadão Mercosul ${ }^{13}$.

Quando as lojas do SCM foram implantadas ao lado das casillas, estas já formavam uma passarela de compras para o cliente de massa. Esse comércio, entretanto, era visto com desconfiança por parte dos brasileiros, fossem comerciantes, moradores de Ponta Porã ou mesmo os turistas de compra elitizados. O ambiente do mercado informal paraguaio,desde aquele momento,era considerado perigoso, espaço da ilegalidade e da ausência de regulamentação e controle públicos, além de ser carente de infraestrutura e serviços adequados, tais como limpeza urbana, segurança pública e áreas para descanso.

Diante dessas deficiências atribuídas à estrutura das casillas, o projeto brasileiro, estruturalmente semelhante ao do vizinho, procurou diferenciar-se pela condição de organização, limpeza, segurança e legalidade. No entanto, o cotidiano do mercado informal na fronteira aproximou o SCM da realidade paraguaia. O improviso, a venda de bugigangas falsificadas, o desrespeito às normas, como a não emissão de notas fiscais, entre outros, definiram o perfil desse centro comercial.

Logo que criada, a "Associação do Primeiro Shopping Calçadão Mercosul" assumiu a condução do projeto e começou a comercializar os boxes.

Fizemos tudo assim em coisa simples e lançamos... a ideia. Aí, começou, então, ... o comerciante brasileiro que estava quebrado do lado de lá [ no centro de Ponta Porã], ele aderiu. Até porque ele já não vendia mais do lado de lá. Então o que ele tinha que fazer? Ele tinha que achar uma alternativa e aí ele veio prá cá. Quando a situação no Brasil melhorou, ele voltou de novo [para o centro da cidade] (Administradora do SCM).

Foram construídos 188 módulos de alumínio, dispostos em dois pavilhões paralelos de aproximadamente $300 \mathrm{~m}$ cada, com uma passarela central para a qual as lojas deveriam convergir. Na proposta

\footnotetext{
${ }^{13} \mathrm{~A}$ fim de facilitar a leitura, o nome do centro comercial será grafado também com a sigla "SCM".
} 
urbanística esse seria o espaço de trânsito dos clientes, onde fariam suas compras e teriam área para descanso e refeições, como lanchonetes e cafés, com mesas montadas na passarela. Nesse desenho, as lojas que margeavam a linha de divisa ficariam de costas para o espaço do canteiro onde se encontravam as casillas, do lado paraguaio, quejá atraíam clientela importante do mercado popular. Tal projeto não se materializou. Na prática as lojas se voltaram para os locais onde havia público, esvaziando a passarela central. Assim, o pavilhão paralelo às casillas abriu suas portas para o lado do Paraguai, enquanto que o seguinte, junto à via pública de Ponta Porã, voltou-se para esta cidade, oferecendo, inclusive, serviços como conserto de celulares e outros que visavam atender às demandas da clientela local.

Essa estratégia transformou o canteiro que separa os países, antes um espaço amplo de livre acesso e trânsito de pessoas, numa inusitada via de comércio, sem pavimentação, arborização ou infraestrutura urbana, margeada pelas casillas e pelas lojas do Shopping Mercosul. O comprador que se dirige ao local, seja a pé, de ônibus ou de vans, pode adquirir seus produtos em qualquer dos lados do corredor de lojas, a despeito de pertencerem a países diferentes e com legislações comerciais específicas.

Aproximadamente 1000 pessoas vivem direta ou indiretamente da renda auferida com o trabalho no camelódromo. O Shopping Calçadão Mercosul possui 15 funcionários, entre vigias, guardas plantonistas, zeladores, secretárias e administrador. Além dos funcionários, contrata serviços jurídicos e de contabilidade. Os 188 boxes empregam um número expressivo de trabalhadores e parentes dos proprietários. O trabalho é, geralmente, de base familiar, "um box tem o proprietário, aí tem a mulher que vive disso. De repente mais dois filhos que vivem disso e um funcionário também, né?", tal como explicou a presidente da Associação.

Somente brasileiros ou estrangeiros legalizados no Brasil podem adquirir uma loja no SCM. "Nós não aceitamos aqui sem o CPF, sem a legalização" (Adminstradora). Muitos dos proprietários são, no entanto, de origem asiática, sobretudo, chineses e taiwaneses, havendo também árabes, em sua maioria libaneses. É comum esses imigrantes adquirem comércio no SCM e registrarem o estabelecimento em nome de algum filho maior de idade nascido ou legalizado no Brasil. Em seguida, empregam toda a família, sejam esposas, filhos, irmãos dos 
pais, sogros, entre outros. Como o controle destina-se a regular a propriedade do local, não se aplicando à origem ou condição contratual de seus empregados, eles se estabelecem sem dificuldades e com o passar do tempo adquirem novas lojas que acabam sendo administradas por outros membros da família.

A Associação possui poder de normatização e controle sobre os estabelecimentos, o que faz mediante regimento interno. Esse dispositivo regula desde o uso do espaço, a disposição das mercadorias, o que pode ser comercializado, até a forma de aquisição e venda dos direitos sobre os boxes. Alguns dispositivos do regulamento, por razões práticas ou de interesse particular, não têm sido respeitados. O cotidiano do comércio trouxe demandas e oportunidades que não estavam previstas no regimento, levando a adaptações que costumam causar problemas para a administração.

[...] foi difícil você segurar, por exemplo, essas varandinhas. Eles foram se adaptando. Essa varanda que tem do lado aqui, ela não era do projeto. Mas, como o sol batia forte!... [E], na verdade, não era prá abrir pro lado [do Paraguai], era prá abrir prá cá! Entendeu? Mas, como os ônibus de turismo paravam lá, ali no meio, eles acabaram virando praquele lado. (Administradora do SCM).

O Shopping Calçadão Mercosul é, na realidade, um camelódromo, semelhante a muitos outros existentes no Brasil. Um dos aspectos que caracteriza a atividade de camelôs tais como os de Brasília - DF, de Campo Grande - MS, de Porto Alegre - RS e de tantas outras cidades brasileiras é o fato de adquirirem seus produtos a baixo custo no Paraguai, para revendê-los, geralmente no contexto da informalidade, a preços populares nas cidades onde possuem seus comércios. Sendo assim, uma pergunta que surge de imediato diante desse projeto diz respeito ao sentido de montar um mercado voltado para o consumidor final num contexto em que ele pode encontrar, à distância de alguns passos, produtos idênticos e com preços mais acessíveis.

\section{A lógica do camelódromo brasileiro}

Diversos são os fatores que contribuíram para fomentar a ideia do camelódromo, bem como para mantê-lo ativo através dos anos. Em 
primeiro lugar, como mencionado anteriormente, o momento em que foi idealizado era de profunda crise no comércio de Ponta Porã. Havia que se encontrar alternativas, propor soluções de mercado a fim de abrigar especialmente os pequenos proprietários locais, os mais vulneráveis diante da conjuntura desalentadora.

Para os comerciantes brasileiros, habituados à lógica da economia fronteiriça, em que as oscilações conjunturais estimulam a manutenção dos negócios ora num ora noutro país, transferir-se para o Paraguai seria a primeira e a mais sensata das alternativas. Porém, com a economia de Pedro Juan Caballero em expansão, o mercado imobiliário local vivia um momento de euforia. Desde a década de 1980 imigrantes chineses, taiwaneses e coreanos instalavam-se na cidade. Assim, adquirir um ponto de venda não era tarefa simples ou, em outros termos, havia se tornado uma empreitada muito dispendiosa. Como informou uma proprietária do SCM, mesmo uma loja de pequeno porte não saía por menos de 30 ou 40 mil dólares. Valor que restringia consideravelmente o acesso do pequeno comerciante aos imóveis melhor localizados no município paraguaio.

Em segundo lugar, a realidade da integração regional de países do Cone Sul, resultante da criação do Mercosul em 1991, era objeto de atenção e de expectativas, sobretudo numa área de fronteira em que os fluxos econômicos estão sujeitos aos humores do mercado internacional. $\mathrm{O}$ advento do tratado do Mercosul apontava para a satisfação de uma demanda histórica da cidade de Ponta Porã, que almejava compartilhar do modelo de comércio reexportador que tantos benefícios trazia à vizinha Pedro Juan Caballero. Para se ter uma ideia de como esse projeto mobilizava a comunidade local basta lembrar que, logo em seguida à sua criação, a Associação do Primeiro Shopping Calçadão Mercosul esboçou, sem sucesso, um movimento junto ao Congresso Nacional visando a implantação de uma Área de Livre Comércio em Ponta Porã, com o objetivo de estabelecer concorrência direta e legalizada com o comércio paraguaio (TORRECILHA, 2004).

Por último, o SCM foi pensado para atender ao turista de compras, aquele que visita o lugar com o objetivo de adquirir produtos destinados ao consumo final (MARTINS, 2007). A fim de competir com as casillas nesse mercado houve, a princípio, uma tentativa de atuar como cooperativa. Os associados adquiriram, por atacado, 
produtos eletrônicos e bugigangas, de pequeno porte e de fácil comercialização, de uma importadora do Rio de Janeiro. Era tudo legalizado, como sustenta a presidente da Associação. O preço das mercadorias, entretanto, ficou $30 \%$ mais elevado do que o praticado no Paraguai. As vendas emperraram. A iniciativa fracassou.

Em seguida, investiram em vestuário, adquirido de confecções brasileiras. O comércio teve êxito relativo, tanto que perdura em algumas lojas até os dias de hoje e em ambos os lados da fronteira. No entanto, os comerciantes perceberam que a sua sobrevivência requeria estratégia mais ousada. Um camelódromo brasileiro, na linha de divisa, competindo com comerciantes paraguaios que gozavam de vantagens tributárias, precisava, no mínimo, equiparar-se em condições de mercado ao concorrente. Assim, começou por mudar o foco na clientela. Não mais o turista de compras, o visitante ocasional ou a população local, mas o mesmo público que frequentava as casillas, ou seja, o sacoleiro, cuja demanda era por produtos importados e em maior quantidade.

Com essa estratégia o camelódromo brasileiro transformou-se numa extensão do paraguaio, com o qual passou a competir pelos clientes. Os produtos oferecidos tornaram-se idênticos e sua origem comum. Mas não apenas coincidem clientes e mercadorias. Em muitos casos, os proprietários dos boxes também são os mesmos. Não raro comerciantes de origem árabe, coreana e chinesa que possuem lojas no SCM - como denunciam as fachadas de boxes que estampam nomes como Casa Mey, Jahanara Center, Hong Kong Center, e seu parônimo Casa King Kong, entre outros - dispõem de um comércio em Pedro Juan Caballero. É comum seus clientes realizarem as compras no Brasil e receberem as mercadorias no Paraguai.

Alguns comerciantes estrangeiros, sobretudo chineses e coreanos, estabelecidos no Paraguai, atuam como importadores de mercadorias de Ciudad del Este ou diretamente da China. São eles que abastecem as casillas em Pedro Juan Caballero, da mesma forma que são os fornecedores dos comerciantes do SCM. Deles os lojistas compram uma infinidade de bugigangas, tais como malas, bolsas, maquiagens, brinquedos, sombrinhas, cobertores, térmicas, entre tantas outras. Sem o recurso a importadores estabelecidos no Brasil, o abastecimento do SCM ficou mais ágil e barato: "a gente atravessa a rua, compra e volta" (Lojista). Os comerciantes brasileiros e os casilleros também 
adquirem mercadorias de representantes de importadoras existentes em Ciudad del Este e na capital, Assunção, que periodicamente visitam a fronteira. Como informa um comerciante, "hoje tá tudo igual: o Paraguai é aqui"!

\section{O ilegal é o "outro"}

No SCM os lojistas são cadastrados, possuem alvará da Prefeitura, pagam taxas e impostos municipais. Os produtos que comercializam, no entanto, transitam constantemente na linha tênue entre a legalidade e a ilegalidade. As mercadorias importadas do Brasil, como o vestuário adquiridos em confecções nacionais, a princípio, são legais, porém, as bugigangas originárias do Paraguai tendem a constituir contrabando. Tal como Pinheiro-Machado (2004) anotou em relação aos sacoleiros e camelôs com que trabalhou na cidade de Porto Alegre, há diversos processos que se sobrepõem nesse negócio, sendo que a relação entre o legal e o ilegal, o lícito e o ilícito se complementam em várias esferas.

Assim, o SCM que nasceu com apoio da Prefeitura em momento de grande consternação pública, com a economia da cidade em crise, passou a constituir um problema para as gestões seguintes. Quando a estabilidade econômica foi retomada, no final da década de 1990, e o projeto, por demandas do mercado e artifícios de sobrevivência, foi se moldando ao comércio informal paraguaio, com todas as suas peculiaridades, surgiram os questionamentos em relação à sua legitimidade. "E aí veio as polêmicas, né? Porque tá na linha... Porque... Cada governo que entra... tinha uma situação. [...] cada governo que entra eles querem mexer um pouco" (Administradora).

Para Pinheiro-Machado (2004 e 2008), definir a informalidade é uma tarefa desafiadora. Se, de um lado, ela se define em oposição a normatizações legais, que variam conforme os países em que são formuladas, de outro, ela é regulada segundo conjunturas locais, que levam em conta aspectos políticos e sociais que não necessariamente se pautam em parâmetros normativos. Como ressalta a autora, em "cada micro contexto [...] há uma grande variação entre a tolerância das autoridades locais em relação à determinada prática mercantil, o que, em certa medida, influenciará nas nuanças de legalidade" (2008, p. 05). Assim, a permanência do mercado informal na linha de 
fronteira decorre não apenas da capacidade de seus agentes de praticar o comércio, atrair clientes com atendimento cortês e preços sedutores, como também das negociações que estabelece rotineiramente com o poder municipal e a opinião pública a fim de estabelecer uma condição de legitimidade que a priori não está assegurada.

Há que se observar que, por constituir-se numa fronteira seca, o cotidiano da população local, que se desloca constantemente entre os países, está pautado em práticas que fogem ao controle dos poderes públicos. A respeito dos hábitos do morador da fronteira, o cronista pedrojuanino Juan Carlos Rivas sustenta que dificilmente as leis podem ser aplicadas integralmente a ponto de coibir práticas corriqueiras, como desobediência a regras de trânsito, a habilitação de eleitores simultaneamente em dois colégios eleitorais, entre outros. Em relação ao consumo, o autor destaca o comércio formiga, realizado em ambos os sentidos da fronteira, observando que "los organismos competentes hacen vista gorda a esta práctica y resulta totalmente natural pasar de um lugar a otro para adquirir un bien que resulte más conveniente, sin que a esto se le dé el rótulo de contrabando" (CENPA, 2008, p.25).

Os hábitos fronteiriços atenuam as críticas, mas não as eliminam. Assim, em meio à polêmica, o discurso dos proprietários de lojas do SCM se atém à defesa da legalidade, advinda da regularização do empreendimento perante o poder público municipal e federal. Frases tais como: "estamos conforme as normas da prefeitura", "somos legalizados", "temos a documentação", entre outras, preenchem constantemente o discurso da presidente da Associação do SCM, bem como de muitos de seus associados ${ }^{14}$.

A essas falas se seguem outras, que complementam o discurso da regularidade proferido pela administração do condomínio: "Nós não aceitamos aqui sem a legalização", "Nós temos um departamento jurídico", "O documento está assinado pela Prefeitura". Frases essas que visam não apenas ressaltar a lisura na conduta administrativa, masque apontam para a existência de práticas antagônicas, o que tende a atenuar, pelo contraste, as faltas que porventura existam no cotidiano do comércio no SCM.

\footnotetext{
${ }^{14}$ Somente foram entrevistados proprietários de nacionalidade brasileira, à exceção de uma comerciante de origem indiana e "casilleros" paraguaios.
} 
Porque a gente procurou nesses anos todos manter, assim, a ordem, pelo menos moral. Nós não permitimos aí venda de CD pirata, arma, questão de prostituição. Esses detalhes não se vendem aqui. $\mathrm{O}$ demais, é camelódromo mesmo. É o mesmo produto que vende no Paraguai (Administradora).

Mesmo que haja práticas ilícitas no SCM, até porque é assumidamente um camelódromo similar ao paraguaio, ou seja, um comércio informal estabelecido numa linha de fronteira, elas se manteriam, na visão de seus lojistas, no escopo do moralmente aceitável. A explicitação das regras de conduta dos comerciantes brasileiros funciona assim como uma espécie de recurso contrastivo. A perspectiva acerca do "outro" revela-se naquilo que o discurso nega em relação ao "nós". As falas têm como contraponto o comércio das casillas, assentado em práticas moralmente reprováveis, tal como a venda de produtos piratas e de armamentos, "típicas" de paraguaios. Os discursos depreciativos são assim validados menos pelo parâmetro da concorrência mercadológica do que por uma condição que se acredita legítima, que é a de "ser" brasileiro.

Porque ali não é que nem aqui. Aqui você vende teu espaço, você tem uma coordenação, tem um departamento jurídico, tem tudo legal, né? Ali não, ali [nas casillas] as pessoas encostaram e já fizeram um espaço prá eles. Aí eles foram na prefeitura, pagaram lá uma propina prá alguém e ali já deixaram ele trabalhando. Aí do lado desocupou ele tomou posse, do outro lado desocupou ele tomou posse, automaticamente. Tem gente que tem mais de 20 espaços ali! Um proprietário só. (Comerciante do SCM).

A corrupção, a desorganização, a insegurança, a sujeira e a propina acentuam o caráter de "ilegalidade", que é visto como característico do "paraguaio". Ainda que o parâmetro sejam as práticas do mercado popular, é o exercício e a consequente afirmação do discurso identitário do brasileiro fronteiriço que se revela nesses depoimentos. O paraguaio seria, então, detentor de costumes e características que o tornam inferior ao brasileiro, mesmo que ambos experimentem situações de trabalho e de convívio cotidianos muito semelhantes e mesmo que o primeiro atue amparado pelas normas que balizam o comércio reexportador de seu país, enquanto que o brasileiro atua numa condição de maior informalidade. Assim, se é inegável que práticas ilícitas permeiam o comércio popular dos brasileiros, elas são 
moralmente compensadas diante da experiência negativa do "outro", pautada, no entender dos lojistas brasileiros, pelo descontrole, pela desorganização e pela ilegalidade inerentes ao "ser" paraguaio.

\section{Conclusão}

Este artigo buscou evidenciar o modo como foi concebido e implantado o centro comercial popular Primeiro Shopping Calçadão Mercosul no contexto do mercado turístico na fronteira entre o Brasil e o Paraguai. O trabalho abordou as condições conjunturais da economia que induziram a construção desse centro comercial e a maneira como se processou a interação de seus lojistas com o mercado paraguaio. Da mesma forma, o artigo procurou discutir de que forma, numa situação de mercado bastante similar, categorias tais como legal e ilegal, lícito e ilícito se articulam no discurso de comerciantes brasileiros com o fim de validar suas práticas e, ao mesmo tempo, imagens e impressões sobre um "outro", mais que concorrente, estrangeiro e historicamente inferiorizado.

Se a noção do que é legal compreende monopólio do Estado, como demonstrado por Ribeiro (2009), e as nuances entre o que é lícito e o que é ilícito são balizadas, em muitos aspectos, pelas relações cotidianas mantidas com o poder público e com as autoridades locais (PINHEIRO-MACHADO, 2009), a experiência do comércio popular de Ponta Porã demonstrou que parâmetros morais e identitários, construídos e reafirmados no convívio cotidiano de povos fronteiriços se interpõem, da mesma forma, como referências de legitimidade de práticas de mercado. Assim, num contexto pautado pelo exercício de atividades não apenas similares, mas interligadas e mutuamente influentes, as diferenças tendem a ser demarcadas por parâmetros exteriores, mantendo as assimetrias que separam o "nós" dos "outros".

O SCM passa atualmente por um processo gradual de transferência para as dependências do Projeto Linha de Fronteira. Das 188 lojas, 40 boxes já se encontram nas novas instalações, enquanto que os demais aguardam a construção do edifício que os abrigará. A economia do turismo de compras vivencia uma crise recentemente deflagrada em decorrência da desvalorização da moeda brasileira. A se confirmar essa conjuntura, o Shopping popular tende a enfrentar grandes desafios de 
mercado, podendo vir a sofrer mudanças significativas em sua estrutura e estratégia de atuação. Investigar a dimensão dessa crise e seus desdobramentos será tarefa importante não apenas na compreensão dos efeitos sobre a economia informal fronteiriça, mas também nas implicações sobre o diálogo entre paraguaios e brasileiros articulado no contexto do mercado turístico.

\section{Referências}

BENÍTEZ, S. A. C. A la sombra de los perobales. Historia del poblado de Punta Porã, génesis de dos ciudades (1870-1902. Imprenta Salesiana (PY), 2008.

CENPA. Centro de Estudios Historicos y Culturales del Nordeste Paraguayo. El Casque. Comunicación y cultura en el Amambay. Abril 2008.

ENGEL, J. M. As comissões brasileiras demarcadoras de limites: breve notícia histórica. <Disponível em http://info.lncc.br/cbdls.html.>. Acessado em janeiro de 2012.

GOIRIS, F. A. J. Descubriendo la frontera: historia, sociedad y política em Pedro Juan Caballero. Ponta Grossa: Inpag, 1999.

GUILLEN, I. C. M. O imaginário do sertão: lutas e resistências ao domínio ao domínio da Companhia Mate Laranjeira (Mato Grosso: 1890 - 1945). Dissertação Mestrado. História. IFCH/UNICAMP, Campinas. 1991.

IBGE - Instituto Brasileiro de Geografia e Estatística. Censo demográfico: 2010. Rio de Janeiro: IBGE, 2010.

LAMBERTI, E. Dinâmica comercial no território de fronteira: reexportação e territorialidade na conurbação Ponta Porã e Pedro Juan Caballero. Dissertação de Mestrado. Geografia. Aquidauana /MS: Universidade Federal de Mato Grosso do Sul, 2006.

MARTINS, P. C. S. A formação do território turístico de Pedro Juan Caballero (Paraguai). Dissertação de Mestrado. Geografia. Aquidauana (MS): UFMS, 2007. 
NORONHA, E. G. "Informal", Ilegal, Injusto: Percepções do Mercado de Trabalho no Brasil. Revista Brasileira de Ciências Sociais, vol.18, n. 53, 2003.

PENNER, R. Movimiento comercial y financiero de Ciudad del Este. Perspectivas dentro del proceso de integración. Banco Central del Paraguay, Gerencia de Estudios Económicos, Asunción, Noviembre de 1998

PINHEIRO-MACHADO, R. A garantia soy yo. Etnografia das práticas comercias entre camelôs e sacoleiros nas cidades de Porto Alegre (Brasil) e Ciudad del Este (Paraguai). Porto Alegre: UFRGS (Mestrado em Antropologia Social), 2004.

China-Paraguai-Brasil: uma rota para pensar a economia informal. Revista Brasileira de Ciências Sociais, N. 67, 2008.

. Made in China. Produção e circulação de mercadorias no circuito China-Paraguai-Brasil. 2009. Tese de Doutorado. Porto Alegre: Programa de Pós Graduação em em Antropologia Social, Universidade Federal do Rio Grande do Sul, Porto Alegre/RS.

QUEIROZ, P. R. C. A grande empresa conhecida como Mate Laranjeira e a economia ervateira na bacia platina (1882-1949): notas preliminares. 2009. Disponível em < http://www.historia.uff.br/ stricto/ files/public_ppgh/2009-12_queiroz.pdf>. Acessado em janeiro de 2012.

Revisitando um velho modelo: contribuições para um debate ainda atual sobre a história econômica de Mato Grosso/Mato Grosso do Sul. InterMeio: Revista do Programa de Pós-Graduação em Educação, Campo Grande, MS, v.14, n.27, p.128-156, jan./jun. 2008.

RABOSSI, F. Nas ruas de Ciudad del Este: vidas e vendas num mercado de fronteira. 2004. Tese de Doutorado. Programa de Pós Graduação em Antropologia, Museu Nacional, Universidade Federal do Rio de Janeiro, Rio de Janeiro.

RENOLDI, B. Tus amigos son mis amigos: relaciones legales e ilegales entre estados de frontera. Buenos Aires. Reunião de 
Antropologia do Mercosul, 2009. <Disponível em http://www.ram2009.unsam.edu.ar.> Acessado em dezembro de 2011.

RIBEIRO, G. L. A globalização popular e o sistema mundial não hegemônico. Revista Brasileira de Ciências Sociais, v. 25, n. 74, out 2010 .

A Globalização Popular e o Sistema Mundial Nãohegemônico. Ou, de Guangdong a Caruaru. Revista Brasileira de Sociologia da Emoção, v.8, n. 24, 510-522, Dez 2009.

SILVA, M. de A. "This isn't contraband, I'm clean"; a study of borders of incorporation and exclusion among Chinese immigrantes in Pernambuco. Brasília : ABA, Vibrant, v.6. n. 1, jan-jun 2009.

TORRECILHA, M. L. A fronteira, as cidades e a linha. Campo Grande/MS: Editora UNIDERP, 2004. 